\title{
Habitat-based intraguild predation by Caribbean reef octopus Octopus briareus on juvenile Caribbean spiny lobster Panulirus argus
}

\author{
Mark J. Butler IV*, Jennifer A. Lear \\ Department of Biological Sciences, Old Dominion University, Norfolk, Virginia 23529, USA
}

\begin{abstract}
Intraguild predation occurs when species simultaneously compete for resources and interact as predator and prey, which describes the interaction between juvenile Caribbean spiny lobster Panulirus argus and Caribbean reef octopus Octopus briareus in the Florida Keys, USA. Octopuses are notorious predators of decapod crustaceans, and their use of crevice shelters suggests that they may also compete for shelter with their lobster prey. Lobsters use mainly chemical cues to detect and avoid octopus, so we hypothesized that the negative association between these species may be as much the consequence of avoidance of a superior competitor as it is of direct predation. Surveys of lobsters and octopuses occupying artificial shelters at 19 hard-bottom sites confirmed that lobsters do not share dens with octopuses, and also show that lobster and octopus abundances are negatively correlated. Tethering experiments on a subset of those sites revealed that predation on lobster was indeed higher on sites with more octopuses. Results from mesocosm studies indicated that although juvenile lobsters do not attain a size refuge from octopus predation, the presence of alternative prey and lobster conspecifics reduces the risk of predation on lobster by octopus. Mesocosm experiments also showed that octopuses were the competitive dominants when shelter was limited. Thus, the negative association between lobster and octopus in the field appears to be driven by both predation and avoidance of octopus-rich sites by lobsters, rather than competition per se. However, crevice shelters suitable for juvenile lobster are limited in many hard-bottom areas in the Florida Keys, so areas where octopuses are abundant may further limit the local accessibility of shelters for juvenile spiny lobsters even if the direct effects of predation by octopus are minimal.
\end{abstract}

KEY WORDS: Asymmetrical competition $\cdot$ Shelter limitation $\cdot$ Size refuge $\cdot$ Priority effects

\section{INTRODUCTION}

Competition and predation impact both population dynamics and community structure (Menge \& Sutherland 1976, Hixon \& Menge 1991), but their simultaneous effects are less well understood (Schmitt 1987, Gurevitch et al. 2000, Chase et al. 2002). Predation can decrease, increase, or have no effect on competitive interactions (Morin 1999, Chase et al. 2002), especially when species simultaneously compete for resources and interact as predators and prey (Polis \& McCormick 1986, Polis et al. 1989, Holt \& Polis 1997,
Guidetti 2007) - an interaction known as intraguild predation (Polis \& McCormick 1986). Intraguild predation can dramatically affect the populations of both species and this phenomenon has been documented in numerous organisms (see Polis et al. 1989, Polis \& Holt 1992, Holt \& Polis 1997 for reviews). The outcome of intraguild predation depends critically on the size of the species involved and priority effects (Holt \& Polis 1997, Omori et al. 2006). Most studies of intraguild predation have emphasized exploitative competition, but it is not clear if the dynamics of intraguild predation are altered when species engage in inter- 
ference competition for resources such as shelter. The interaction between the Caribbean reef octopus Octopus briareus and juvenile Caribbean spiny lobster Panulirus argus is potentially an example of intraguild predation involving interference competition for shelter.

The Caribbean reef octopus and juvenile Caribbean spiny lobster co-occur throughout the Caribbean and occupy similar types of crevice shelters (e.g. coral heads, sponges, and solution holes) (Hanlon 1983, Aronson 1986, Smith \& Herrnkind 1992, Herrnkind \& Butler 1994, 1997) within shallow, hard-bottom habitats. Shelter availability significantly impacts the survival and recruitment of juvenile lobsters (Smith \& Herrnkind 1992, Mintz et al. 1994, Herrnkind \& Butler 1997, Bertelsen et al. 2009), as does the presence of conspecifics for this social species (Eggleston et al. 1997, Childress \& Herrnkind 1996, Mintz et al. 1994). Octopuses are similarly dependent on crevice shelters for protection (Ambrose 1982, Hanlon 1983, Aronson 1986, Anderson 1997), but are solitary. Crevices suitable for juvenile lobster are limited in many hard-bottom areas (Butler et al. 1995, Herrnkind \& Butler 1997, Herrnkind et al. 1997); therefore, areas with abundant octopuses may further limit the local abundance and shelter use of juvenile spiny lobsters because lobsters can detect the presence of octopuses and avoid shelters containing them (Berger \& Butler 2001). The response of lobsters to octopuses is particularly dramatic because lobsters do not respond to chemical cues associated with crevice-dwelling fish predators, such as red grouper (M. J. Butler unpubl. data). The majority of studies involving predation on juvenile Panulirus argus (e.g. Herrnkind \& Butler 1986, Eggleston et al. 1997, Smith \& Herrnkind 1992, Schratwieser 1999) have focused on piscine predators. Although octopuses are notorious predators of lobsters (Cousteau \& Diolé 1973, Joll 1977, Anderson 1997, Boyle 1997), most of what we know about their interaction is based on anecdotal accounts or limited observations (Aronson 1986, Smith \& Herrnkind 1992, Mintz et al. 1994, Anderson 1997, Boyle 1997).

To understand the predator-prey and competitive relationship between juvenile spiny lobster and octopus we conducted a series of field surveys, tethering experiments, and mesocosm manipulations to address the following questions: (1) What relationships exist between the population abundances and patterns of shelter use for both species in the field? (2) Does predation on juvenile lobster increase with octopus abundance? (3) Does a size refuge from octopus predation exist for juvenile lobsters? and (4) How do alternative prey, lobster density, lobster size, and initial residency affect shelter competition and predation dynamics between these species?

\section{MATERIALS AND METHODS}

Study area. Our study sites were in shallow $(<3 \mathrm{~m})$, hard-bottom habitat within the Florida Keys National Marine Sanctuary, Florida, USA. All sites contained artificial shelters that had been placed there several years earlier to augment natural shelter for other experimental studies on lobster. We capitalized on the presence of the artificial structures so we could estimate the abundance of octopus on the sites. Octopuses are otherwise very difficult, if not impossible, to enumerate in natural dens because of their remarkable capabilities of both camouflage and contraction through the smallest openings (Hanlon et al. 2009). Thus, no one has attempted to count octopuses in dens in the wild, only those moving around exposed in the open (Aronson 1986, 1989). Each $25 \times 25$ m site contained 12 to 60 artificial shelters (double-stacked, concrete partition blocks) spaced approximately $2 \mathrm{~m}$ apart in a rectangular array. Each artificial shelter contained 6 crevices $(4 \times 9 \times 30 \mathrm{~cm}$, height $\times$ width $\times$ depth $)$ that accommodate similar numbers and sizes of juvenile lobsters as natural shelters (Herrnkind \& Butler 1997). Octopuses also readily accept them as shelter and brood young in them during the spring reproductive period (Lear 2004). Natural shelters such as sponges, octocorals, hard corals, and small solution holes were also abundant on each site and are indicative of the types of natural structures that are used as dens by both species.

Octopus, lobster, and habitat abundance relationships. To examine the potential relationships between the abundance and size structure of lobster and octopus, we conducted 53 field surveys from July 2001 to July 2003 at 19 sites scattered throughout the Florida Keys. During each survey, we examined all artificial shelters on each site and counted the number of lobsters and octopuses in each. We did not attempt to estimate octopus abundance in natural shelters (as noted above), but we conducted a 30 min census of lobsters found in natural shelters (see Herrnkind \& Butler 1997, Herrnkind et al. 1997). All of the lobsters we encountered on a site were measured (carapace length in $\mathrm{mm}$; $\mathrm{CL}$ ), and their sex and injuries noted. To estimate the abundance of natural shelters on each site, we counted and identified all structures $>20 \mathrm{~cm}$ in diameter within 4, non-overlapping $25 \times 2 \mathrm{~m}$ belt transects.

We compared the mean number of lobsters and octopuses per artificial shelter per site using a Spearman's correlation analysis because the data did not meet the normality and linearity assumptions of the parametric analysis and no transformation was suitable. We used the number of animals per shelter to standardize abundance estimates because the field sites contained different numbers of artificial shelters. 
We used multiple regression analyses to examine relationships between lobster or octopus abundance and other independent variables that might provide clues as to the predatory or competitive nature of their interaction. We examined whether the number of juvenile lobsters in artificial or natural shelters was related to octopus abundance, natural shelter density, and artificial shelter density on a site. We investigated whether juvenile lobster abundance in both natural and artificial shelters, natural shelter density, and artificial shelter density on a site affects the abundance of octopus dwelling in artificial shelters. We determined if the proportion of lobsters with injuries on a site could be explained by octopus abundance, lobster abundance, or the abundance of both natural and artificial shelters. Finally, we examined whether the mean number of injuries per injured lobster (i.e. severity of injury to individual lobsters as opposed to the number of lobsters that are injured) could be predicted from octopus, lobster, or shelter abundance. To determine if octopus presence influences the size distribution of lobsters on a site, we ran 4 separate linear regressions with the mean CL of lobsters, SD of lobster CL, kurtosis of lobster CL, and skewness of lobster CL on a site as the dependent variables and the number of octopus on a site as the independent variable. By examining SD, kurtosis, and skewness of the lobster populations in relation to octopus density we could more thoroughly test the potential impact of octopus on lobster size distribution.

Aggregation with conspecifics increases the survival of lobsters subject to predation (Smith \& Herrnkind 1992, Mintz et al. 1994, Butler et al. 1999, Dolan \& Butler 2006); therefore, we also investigated whether the presence of octopuses on a site effected the local pattern of lobster aggregation in artificial shelters. First, we calculated a standardized Morisita's index of dispersion $\left(I_{\delta}\right)$ for each site to determine if the lobsters present were evenly distributed $\left(I_{\delta}<0\right)$, randomly distributed $\left(I_{\delta}=0\right)$, or clumped $\left(I_{\delta}>0\right)$. We then used multiple regression analysis to determine if the index of dispersion could be predicted from some combination of octopus abundance, lobster abundance, natural shelter density, or artificial shelter density. Using multiple regression, we also examined whether octopus abundance, lobster abundance, artificial shelter density, or natural shelter density impact the mean size of lobster aggregations per site. Often, the data used in the multiple regression did not meet the assumptions of normality and homogeneity of variance and no transformation was suitable. However, with a sufficient sample size, multiple regression is robust to such departures (Zar 1999) and inspection of our results run on rank-transformed data yielded equivalent conclusions.
Lobster mortality in the wild. We conducted a tethering experiment to compare predation and frequency of injury among juvenile lobsters on sites that varied in octopus abundance. We tethered 20 lobsters at each of 7 survey sites where octopus abundance ranged from 2 to 14 ind. site ${ }^{-1}$. Lobsters were tethered to bricks via a $1 \mathrm{~m}$ long strand of $11 \mathrm{~kg}$ test monofilament, as described and used successfully in numerous other studies (see Herrnkind \& Butler 1986, Smith \& Herrnkind 1992, Mintz et al. 1994, and others). A total of 140 lobsters were tethered ranging in size from 20 to $45 \mathrm{~mm} \mathrm{CL}$, corresponding to the size range of juvenile lobsters that naturally co-occurred with octopus on the sites; the sizes of tethered lobsters were the same on all sites. Lobsters were tethered $2 \mathrm{~m}$ apart in a line through the center of the array of artificial shelters. Lobsters were tethered close enough to natural structures so that they could be next to one in order to minimize the stress of being in the open during daylight, but far enough away so that they did not become tangled and lose their ability to defend themselves. It is evident that tethering renders them more susceptible to predation; however, it is a useful tool when comparing relative rates of predation between various predator densities. We did not observe any artifacts of tethering (see Peterson \& Black 1994) that affected our relative comparisons of lobster mortality among sites. Tethering has proven to be a reliable method for discerning differences in relative mortality of lobster among sites (Mills et al. 2008) without the bias of treatment $\times$ artifact interactions (Barshaw et al. 2003). The presence or absence of lobsters and any injuries they sustained were recorded after 24 and $48 \mathrm{~h}$. Lobsters rarely escape from properly constructed tethers (Butler et al. 1999); if lobsters were absent, we considered them to have been killed by a piscine predator if the tether was cut or if only a tiny fragment of the lobster's carapace remained. Lobsters killed by octopus were conspicuous and identified by the presence of an empty, dismembered exoskeleton (Lavalli \& Spanier 2001). Laboratory observations of tethered lobsters consumed by octopus provided visual confirmation of octopus predation on field tethered lobsters. In the present study, all of the tethers were cut or exoskeleton remains were present whenever lobsters were missing; thus, we believe that no lobsters escaped their tethers.

To determine if predation on tethered lobsters increased with octopus abundance, we ran a linear regression examining the relationship between octopus abundance and octopus-induced lobster mortality. We also used linear regression to examine the relationship between the number of piscine-killed lobster and the number of octopus per site and, separately, the proportion of surviving but injured lobsters versus the number of octopus on each site. 
Size refuge from predation. To determine if juvenile lobsters attain a size refuge from octopus predation, we conducted mesocosm experiments in plastic wading pools (1.5 m diam., $0.3 \mathrm{~m}$ deep) at the Keys Marine Laboratory on Long Key, Florida. Each pool contained a single artificial shelter and a single octopus of known size. A lobster ranging in size from 15 to $55 \mathrm{~mm}$ CL was added to each pool and checked twice daily to quantify its survival. Lobsters were removed from the pool after $3 \mathrm{~d}$ if they were still alive. A total of 22 octopuses were used in the present study and they consumed 150 lobsters. Lobsters killed during the competition and lobster mortality trials (see below) were also included in the analysis. We used linear regression to examine the relationship between octopus weight $(\mathrm{g})$ and the $\mathrm{CL}$ $(\mathrm{mm})$ of the consumed lobsters.

Context-dependent competition and predation. To examine if shelter competition and predation between lobsters and octopuses was context-dependent, we manipulated: (1) lobster density (1 or 3 lobsters), (2) the presence or absence of an alternative prey source (live pink shrimp Farfantepenaeus duorarum), (3) the initial resident (lobster or octopus first), and (4) lobster size $(15-25,25-35$ and $35-45 \mathrm{~mm} \mathrm{CL})$ in mesocosm experiments. Three artificial shelters offering different-sized dens were added to each mesocosm $(1.5 \mathrm{~m}$ diam., $0.3 \mathrm{~m}$ deep plastic wading pools): one with 3 large crevices $(9 \times 4 \times 30 \mathrm{~cm})$, one with 3 medium-sized crevices $(6 \times$ $4 \times 30 \mathrm{~cm})$, and the third with 3 small crevices $(3 \times 4 \times$ $9 \mathrm{~cm}$ ). Preliminary studies showed that octopuses and lobsters both select a shelter within $24 \mathrm{~h}$ and usually continue to use that shelter for several days thereafter. Therefore, each trial in this experiment ran for $48 \mathrm{~h}$. On the first morning of a trial a single lobster, 3 lobsters, or an octopus was added to each pool. The following morning (Day 2), the shelter chosen by the initial resident(s) was recorded, alternative prey were added if applicable to that experiment and either an octopus or lobster(s) added to the mesocosm to serve as a new arrival. On the morning of Day 3 (48 h after the trial began), the shelter chosen by all individuals of both species was noted, as were all injuries or mortalities of lobster. For trials using 3 lobsters, data were recorded for all 3 individuals, but only the data from one randomly pre-selected focal individual was used in the analysis.

A total of 10 to 12 trials were run for each treatment group (24 total treatment groups), and all animals were randomly assigned to treatments. Four response variables were analyzed from the trials: lobster mortality, shelter switching, displacement, and lobster aggregation. These data were analyzed using 3 different 4 -way multidimensional log-linear contingency table analyses (initial resident $x$ alternative prey $\times$ lobster density $\times$ outcome of the trial). Each analysis tested for differ- ences in lobster mortality (killed or not killed), shelter switching (whether initial resident switched shelters or not after the addition of the other species), and displacement of each species (initial resident displaced from its original shelter or not after the addition of the other species). Lobster size had no affect on the outcome of the trials; therefore it was excluded from the analyses, yielding 4 -way instead of 5 -way analyses. Due to high lobster mortality in many of the treatments, an analysis was not possible on lobster injury rates. A 4th multidimensional log-linear contingency table was run to determine the affect of the presence of an octopus predator and alternative prey on lobster aggregation (lobsters aggregated in one shelter or not) (3-way analysis; aggregation $\times$ octopus presence $\times$ alternative prey). All data analyses were run on SPSS v.10.0.

\section{RESULTS}

\section{Octopus, lobster and habitat abundance relationships}

Lobster abundance on hard-bottom sites declined significantly with increasing numbers of octopus (Spearman correlation: $\mathrm{r}=-0.315, \mathrm{~N}=50, \mathrm{p}=0.026$ ) (Fig. 1). Variation in lobster abundance was greatest in areas lacking octopuses, but dropped to a consistently low level $\left(\leq 0.5\right.$ lobster block $\left.{ }^{-1}\right)$ with 3 or more octopuses $\left(\sim 0.1\right.$ octopus block $\left.{ }^{-1}\right)$, suggesting a strong threshold effect. The negative effect of octopuses on lobster abundance was true for lobsters living in both artificial and natural shelters $\left(\mathrm{R}^{2}=0.321, \mathrm{~N}=50, \mathrm{p}=\right.$ 0.027). Shelter density, whether natural or artificial, had no effect on lobster abundance (natural shelter: $\mathrm{R}^{2}=0.194, \mathrm{~N}=50, \mathrm{p}=0.173$; artificial shelter: $\mathrm{R}^{2}=$ $0.201, N=50, p=0.151)$ or the density of octopus on a site (natural shelter: $\mathrm{R}^{2}=0.260, \mathrm{~N}=50, \mathrm{p}=0.064$; artificial shelter: $R^{2}=0.146, N=50, p=0.294$ ).

There was one outlier in the data set wherein both lobster and octopus abundance was remarkably high. This outlier, and 2 other data points from that same field site, was removed from the analysis because this site is atypical of natural conditions. The site is situated within a large region wherein natural shelters are scarce due to a mass die-off of sponges that took place over a decade ago (Butler et al. 1995, Herrnkind et al. 1997). Therefore, the artificial shelters on this site are essentially the only shelters available over a large area and thus tend to unnaturally concentrate both species.

The proportion of lobsters per site with injuries was not significantly affected by the density of octopus, lobster, or shelters $\left(\mathrm{R}^{2}=0.011, F=1.137, \mathrm{df}=4, \mathrm{p}=\right.$ 0.351). Lobster, octopus, and shelter abundance also 


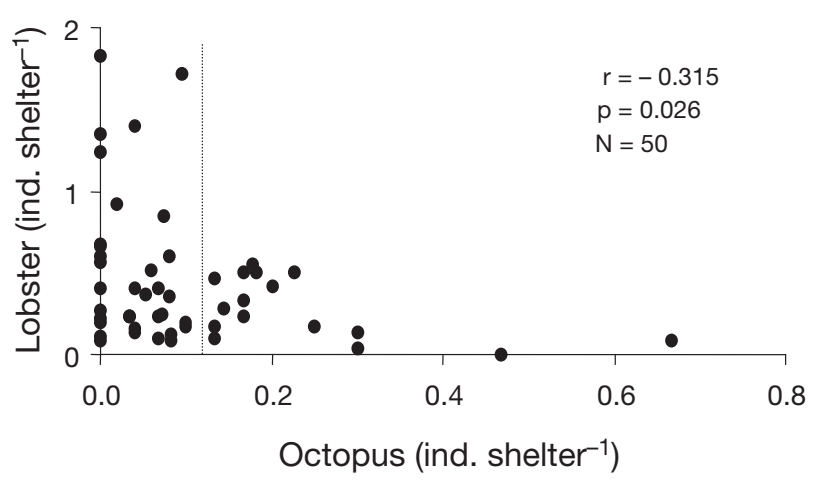

Fig. 1. Panulirus argus and Octopus briareus. Relationship between lobster and octopus abundance in artificial shelters on eighteen $25 \times 25 \mathrm{~m}$ sites in the Florida Keys surveyed a total of 50 times. The dotted line represents a potential threshold effect of octopus density

had no impact on the mean number of injuries sustained per injured lobster per site $\left(\mathrm{R}^{2}=0.025, F=\right.$ 0.790, df $=4, \mathrm{p}=0.541$ ).

Octopus also did not affect the size distribution of lobsters, unlike fish predators that selectively prey upon small lobsters, negatively skewing the size distribution (i.e. red grouper, Schratwieser 1999). The mean size (CL) of lobster $\left(\mathrm{R}^{2}=0.021, F=0.002, \mathrm{p}=0.888\right)$, SD of $\mathrm{CL}\left(\mathrm{R}^{2}=0.022, F=0.002, \mathrm{p}=0.966\right)$, skewness of lobster size distributions $\left(\mathrm{R}^{2}=0.014, F=0.345, \mathrm{p}=\right.$ $0.560)$, and kurtosis of lobster size distributions $\left(\mathrm{R}^{2}=\right.$ $0.009, F=0.606, \mathrm{p}=0.440$ ) were not altered by the presence of octopus.

Octopus abundance, lobster abundance, and the density of natural and artificial shelters had no affect on the spatial distribution of lobsters $\left(\mathrm{R}^{2}=0.032, F=\right.$ 0.816 , df $=4, p=0.530$ ). On average, lobsters were aggregated on each site (i.e. $I_{\delta}>0$ ) regardless of the abundance of predators, conspecifics, or shelter. When aggregated in a shelter, lobsters were generally found in groups of 2 to 4 individuals and group size (i.e. mean no. lobsters aggregation ${ }^{-1}$ ) was not influenced by the abundance of octopus, conspecifics, or shelter $\left(\mathrm{R}^{2}=\right.$ 0.083, $F=1.428, \mathrm{df}=4, \mathrm{p}=0.273$ ).

\section{Lobster mortality in the wild}

Predation by octopus on juvenile lobsters increased with the abundance of octopus on a site $\left(\mathrm{R}^{2}=0.838, F=\right.$ 32.036, $\mathrm{p}=0.002$ ). However, there was no relationship between octopus abundance and the number of injuries sustained by surviving lobsters $\left(\mathrm{R}^{2}=0.453, F=\right.$ 5.977, $\mathrm{p}=0.058$ ) or the number of lobsters judged to have been killed by fish $\left(\mathrm{R}^{2}=0.194, F=0.024\right.$, $\mathrm{p}=$ 0.884).

\section{Size refuge from predation}

There was no relationship between octopus weight and the size of juvenile lobsters they consumed $\left(\mathrm{R}^{2}=\right.$ $0.010, N=148, p=0.112$ ), suggesting that juvenile lobsters do not attain a size refuge from octopus predation. Thus, all size ranges of juvenile lobsters found cohabitating in hard-bottom habitats with octopus are susceptible to octopus predation.

\section{Context-dependent competition and predation}

Initial residency, the presence of alternative prey, and the presence of conspecifics $\left(\chi^{2}=12.787, \mathrm{df}=5, \mathrm{p}=\right.$ $0.0255)$ combine to influence octopus predation on lobster (Fig. 2). Lobster mortality was lowest at high lobster densities, particularly when a lobster was the initial resident of a den $\left(\chi^{2}=5.621, \mathrm{df}=1, \mathrm{p}=0.0178\right.$; Fig. 2A) and when alternative prey were available

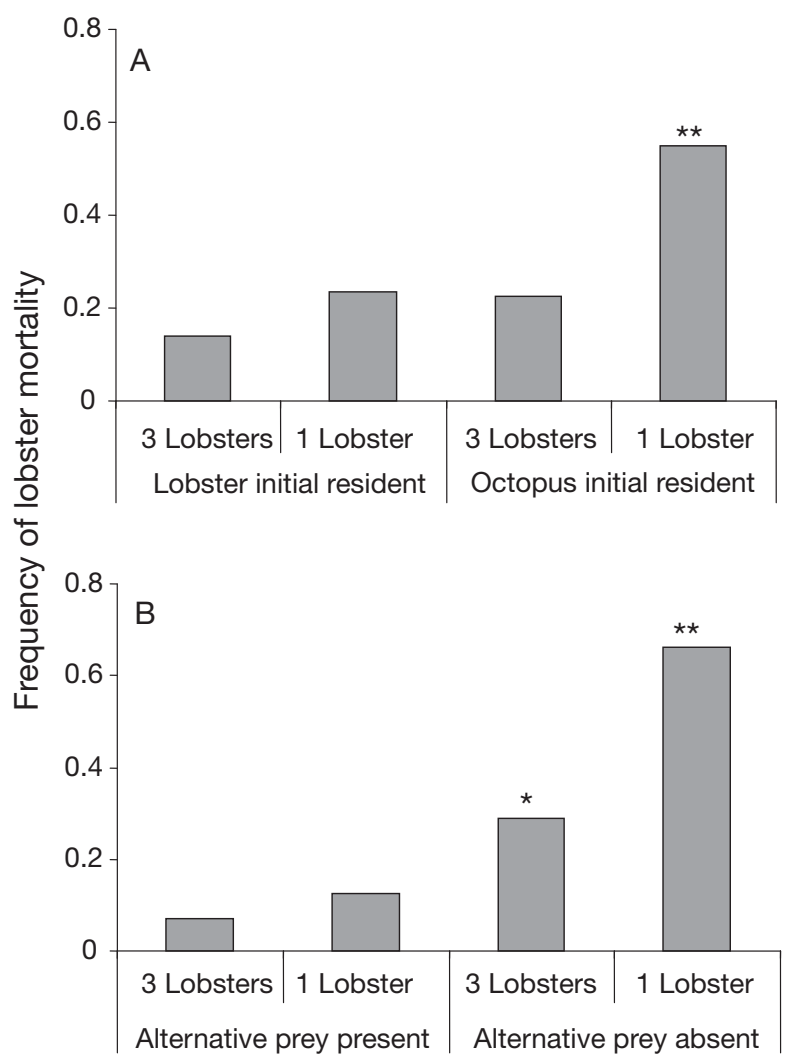

Fig. 2. Panulirus argus. Results of experiments testing (A) the effect of initial residency and lobster aggregation (1 or 3 lobsters) and (B) the presence of alternative prey and lobster aggregation (1 or 3 lobsters) on lobster mortality due to octopus. In both panels, $\mathrm{N}=24$ independent trials. Asterisks indicate that treatments are significantly different at the ${ }^{*} 0.001$ or ${ }^{* *} 0.004$ level 


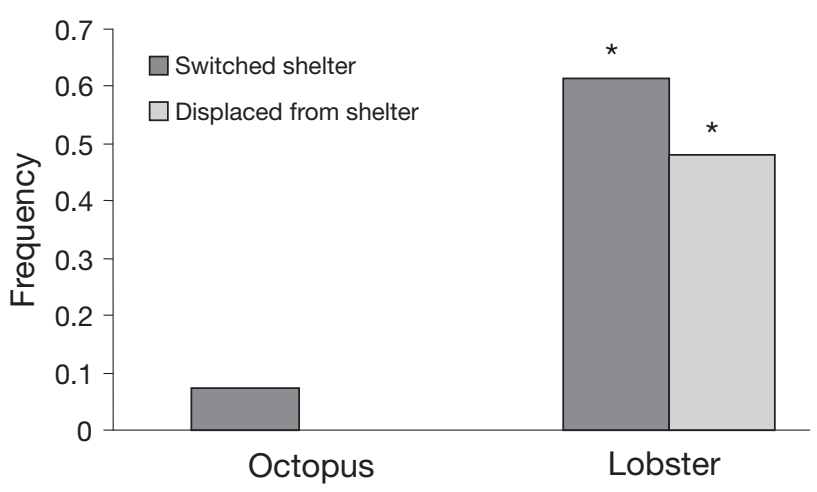

Fig. 3. Panulirus argus and Octopus briareus. Results of a shelter competition experiment testing whether lobsters or octopuses switched shelters or were displaced from a shelter. $\mathrm{N}=108$ independent trials. *: significantly different at the 0.0001 level

$\left(\chi^{2}=5.205, \mathrm{df}=1, \mathrm{p}=0.0225\right.$; Fig. 2B). Lobster size had no effect on mortality, consistent with our other results demonstrating that juvenile lobsters do not attain a size refuge from predation by octopus.

The presence of alternative prey or octopus had no affect on the frequency with which lobsters aggregated in dens $\left(\chi^{2}=0.034\right.$, df $\left.=2, p=0.9833\right)$ or their patterns of movement among dens $\left(\chi^{2}=1.416\right.$, $\mathrm{df}=1$, $\mathrm{p}=0.2340$; Fig. 3), perhaps reflecting the 'hard-wired' sociality of juvenile Panulirus argus. However, resident lobsters switched shelters significantly more often after the addition of an octopus, whereas octopus rarely switched shelters after lobster(s) entered the mesocosm $\left(\chi^{2}=78.732\right.$, df $\left.=1, \mathrm{p}<0.0001\right)$ (Fig. 3). Often, the movement of lobsters from one den to another was a direct result of displacement by octopus $\left(\chi^{2}=25.864, \mathrm{df}=1, \mathrm{p}<0.0001\right)$ (Fig. 3). None of the octopuses that switched shelters were displaced by a lobster. This highlights the asymmetrical response of octopus and lobster to each other.

\section{DISCUSSION}

The strongest interactions between species occur when prey simultaneously compete for a limited resource and are subject to predation by their competitor (i.e. intraguild predation; see Polis et al. 1989, Morin 1999). For the prey species to persist under these circumstances it must either be the superior competitor for the resource or evolve behaviors or benefit from circumstances that reduce its mortality (e.g. size refuge, priority effect; see Polis et al. 1989, Holt \& Polis 1997, Morin 1999). Alternatively, intraspecific competition or predation by other species may, in turn, keep the predator population at levels that permit the persis- tence of the prey species. Increased productivity (i.e. shared resources) could also facilitate the coexistence of both predator and prey subject to intraguild predation (see Morin 1999). Mediating factors such as these are particularly important in situations where intraguild predation is asymmetrical-that is, when the predator is also the superior competitor (Polis et al. 1989, Armsby \& Tisch 2006). Such is the situation between juvenile Caribbean spiny lobster and the Caribbean reef octopus.

Both lobsters and octopuses inhabited similar types of natural shelters, and both readily occupied the artificial shelters that we deployed in the present study. Yet when octopuses were abundant, lobsters were few and lobster mortality significantly increased when more than 2 octopuses occurred on a site. This negative pattern could reflect either the avoidance of octopus by lobster (non-lethal effect) or direct mortality. We suspect that chemical detection of octopus by lobster, lobster agility, the presence of lobster conspecifics for group defense, and the availability of alternative prey all contribute to the coexistence of lobster and octopus and diminish the importance of direct mortality in explaining their negative association at the local scale.

Berger \& Butler (2001) demonstrated that juvenile Panulirus argus avoid the chemical scent of Octopus briareus, which in turn alters the spatial distribution of lobsters in the wild. Lobsters are rarely found within $5 \mathrm{~m}$ of an octopus den. Chemoreception is an effective means by which many organisms detect their predators (Zimmer-Faust 1989, Kats \& Dill 1998), and other species such as hermit crabs and gastropods chemically detect and avoid octopus (Fawcett 1984, Brooks 1991). Indeed, the non-lethal effects of predators on prey behavior, growth, reproduction, and habitat use are a widespread and potent phenomenon that influences the population dynamics of animals living in terrestrial, freshwater, and marine ecosystems (see Lima 1998, Fedriani et al. 2000). The ability to chemically detect octopuses is advantageous because the rapid tail-flip escape response of lobsters allows them to avoid octopuses once they are detected (Joll 1977). Others have suggested that spiny lobster prefer dens with multiple entrances (Spanier \& Zimmer-Faust 1988), which would also be effective in avoiding slowmoving predators like octopus. In contrast, there is no evidence that spiny lobsters use olfactory cues to detect and avoid piscine predators (Schratwieser 1999), nor would flight or multiple den entrances seem a particularly valuable strategy for evading fastswimming fish predators. Instead, group defense by spiny lobster is a well-documented and effective means of reducing piscine predation (Mintz et al. 1994, Eggleston et al. 1997, Butler et al. 1999, Dolan \& Butler 
2006), and our results demonstrate that it is also effective against octopuses. Alternatively, multiple lobsters fleeing an octopus predator in a confined space may have lessened predation due to a confusion effect on the octopus (Neill \& Cullen 1974).

The presence of alternative prey also reduced lobster mortality in our mesocosm experiments, a subtlety often lost in simple, 2-species laboratory experiments. Alternative prey such as crabs and shrimps are often abundant where lobster dwell and are the most common prey for many species of octopus, including Octopus briareus (Boyle 1983, Schmitt 1987). Crevicedwelling juvenile lobsters are a relatively large and formidable prey for the diminutive $O$. briareus, and probably are not its dominant prey unless other prey are scarce or the lobster is isolated and constrained in a den, laboratory tank, or by a tether. Unlike other species of octopus that transport their prey to their den for consumption, forming middens of prey carcasses, $O$. briareus does not typically do so. Thus, one cannot ascertain the typical prey of $O$. briareus in the field in this way. We only rarely see evidence of octopus predation on lobsters in the field (i.e. the dismantled pile of body parts so characteristic of octopus predation), except in lobster traps where lobsters cannot flee or effectively defend themselves.

When we began the present study, we hypothesized that besides their predator-prey relationship, juvenile lobster and octopus might compete for access to shelter because of their similar shelter requirements and evidence from studies of juvenile lobster indicate that shelter can limit recruitment of lobster in some areas (Herrnkind \& Butler 1997, Herrnkind et al. 1997). In this system, shelter limitation can also be episodic and catastrophic. For example, portions of the Florida Keys have experienced repeated blooms of cyanobacteria that cause mass die-offs of sponges, which destroy shelters used by juvenile lobsters and diminishes lobster abundance (Butler et al. 1995, Herrnkind et al. 1997). Further changes in habitat structure and crevice shelter availability are expected in Florida Bay due to restoration efforts in the Everglades (Butler 2003). Although comparable studies on octopus do not exist, octopus populations might be similarly influenced by reduced shelter availability. Our mesocosm results suggest that if shelter were limited, octopus would indeed be the superior competitor, capable of displacing resident lobster. However, situations where lobsters are shelter-limited may not apply to octopus, which are probably more plastic in their use of shelter-they are renowned contortionists, capable of exploiting a wider range of shelters.

Octopuses are effective predators of juvenile lobsters, they are superior competitors for the same types of shelter used by lobsters, and lobsters avoid areas where octopuses dwell. Thus, ascribing the octopus-lobster relationship as either a predator-prey or competitive interaction is an oversimplification. It is better characterized as asymmetrical intraguild predation (Polis et al. 1989). Too often we seek the elegantly simple solution to our questions about ecological processes and design our experiments in ways that reinforce that perspective. In contrast, our study of octopus-lobster interactions supports the importance of investigating the contextual dependency of competition and predation. For lobsters, it appears that grouping with conspecifics for defense, their ability to chemically detect and avoid octopus, and the presence of alternative prey reduces their mortality and allows for their regional coexistence with octopus. However, high densities of octopus result in the local extirpation of lobster via direct (predation) and indirect (predator avoidance) mechanisms.

Acknowledgements. We thank D. Behringer and S. Donahue for their help in the field and laboratory. Two anonymous reviewers along with C. Binckley, T. Dolan, K. Kauffman, M. Kintzing and J. Weisz provided helpful comments on early versions of the manuscript. This research was supported by grants from the NOAA Coastal Ocean Program (NA160P2561) and the National Science Foundation (OCE9730195) to M.J.B.

\section{LITERATURE CITED}

Ambrose RF (1982) Shelter utilization by the molluscan cephalopod Octopus bimaculatus. Mar Ecol Prog Ser 7: $67-73$

Anderson TJ (1997) Habitat selection and shelter use by Octopus tetricus. Mar Ecol Prog Ser 150:137-148

Armsby M, Tisch N (2006) Intraguild predation and cannibalism in a size-structured community of marine amphipods. J Exp Mar Biol Ecol 333:286-295

Aronson RB (1986) Life history and den ecology of Octopus briareus Robson in a marine lake. J Exp Mar Biol Ecol 95: $37-56$

Aronson RB (1989) The ecology of Octopus briareus Robson in a Bahamian saltwater lake. Am Malacol Bull 7:47-56

Barshaw DE, Lavalli KL, Spanier E (2003) Offense versus defense: responses of three morphological types of lobster to predation. Mar Ecol Prog Ser 256:171-182

Berger DK, Butler MJ IV (2001) Octopuses influence den selection by juvenile Caribbean spiny lobster. Mar Freshw Res 52:1049-1053

Bertelsen RD, Butler MJ IV, Herrnkind WF, Hunt JH (2009) Regional characterization of hard-bottom nursery habitat for juvenile Caribbean spiny lobster using rapid assessment techniques. N Z J Mar Freshw Res 43:299-312

Boyle PR (1983) Cephalopod life cycles, Vol. I: species accounts. Academic Press, London

Boyle PR (1997) Octopus interactions with crustacean fisheries. In: Lang MA, Hochberg FG, Ambrose RA, Engle JM (eds) Workshop on the fishery and market potential of octopus in California. Smithsonian Institution Office of the Provost Scientific Diving Program, Washington, DC, p 125-129 
Brooks WR (1991) Chemical recognition by hermit crabs of their symbiotic sea anemones and a predatory octopus. Malacologia 216/217:291-295

Butler MJ IV (2003) Incorporating ecological process and environmental change into spiny lobster population models using a spatially-explicit, individual-based approach. Fish Res 65:63-79

Butler MJ IV, Hunt JH, Herrnkind WF, Childress M and others (1995) Cascading disturbances in Florida Bay, USA: cyanobacteria blooms, sponge mortality, and implications for juvenile spiny lobsters Panulirus argus. Mar Ecol Prog Ser 129:119-125

Butler MJ IV, MacDiarmid AB, Booth JD (1999) The cause and consequence of ontogenetic changes in social aggregation in New Zealand spiny lobsters. Mar Ecol Prog Ser 188: 179-191

Chase JM, Abrams PA, Grover JP, Diehl S and others (2002) The interaction between predation and competition: a review and synthesis. Ecol Lett 5:302-315

Childress MJ, Herrnkind WF (1996) The ontogeny of social behavior among juvenile Caribbean spiny lobsters. Anim Behav 51:675-687

Cousteau JY, Diolé P (1973) Octopus and squid: the soft intelligence. Doubleday \& Company, Garden City, NY

> Dolan TW III, Butler MJ IV (2006) Modeling ontological changes in the social behavior of juvenile Caribbean spiny lobster, Panulirus argus. J Crustac Biol 26:565-578

Eggleston DB, Lipcius RN, Grover JJ (1997) Predator and shelter-size effects on coral reef fish and spiny lobster prey. Mar Ecol Prog Ser 149:43-59

Fawcett MH (1984) Local and latitudinal variation in predation on an herbivorous marine snail. Ecology 65:1214-1230

Fedriani JM, Fuller TK, Sauvajot RM, York EC (2000) Competition and intraguild predation among three sympatric carnivores. Oecologia 125:258-270

Guidetti P (2007) Predator diversity and density affect levels of predation upon strongly interacting species in temperate rocky reefs. Oecologia 154:513-520

- Gurevitch J, Morrison JA, Hedges LV (2000) The interaction between competition and predation: a meta-analysis of field experiments. Am Nat 155:435-453

Hanlon RT (1983) Octopus briareus. In: Boyle PR (ed) Cephalopod life cycles, Vol I: species accounts. Academic Press, London, p 251-266

- Hanlon RT, Chiao CC, Mäthger LM, Barbosa A, Buresch KC, Chubb C (2009) Cephalopod dynamic camouflage: bridging the continuum between background matching and disruptive coloration. Philos Trans R Soc Lond B Biol Sci 364:429-437

> Herrnkind WF, Butler MJ IV (1986) Factors regulating postlarval settlement and juvenile microhabitat use by spiny lobsters Panulirus argus. Mar Ecol Prog Ser 34:23-30

> Herrnkind WF, Butler MJ IV (1994) Settlement of spiny lobster, Panulirus argus (Latreille, 1804), in Florida: Pattern without predictability? Crustaceana 67:46-64

> Herrnkind WF, Butler MJ IV (1997) A test of recruitment limitation and the potential for artificial enhancement of spiny lobster (Panulirus argus) populations in Florida. Can J Fish Aquat Sci 54:452-463

> Herrnkind WF, Butler MJ IV, Hunt JH, Childress M (1997) Role of physical refugia: implications from a mass sponge die-off. Mar Freshw Res 48:759-769

Hixon MA, Menge BA (1994) Species diversity: prey refuges modify the interactive effects of predation and competition. Theor Popul Biol 39:178-200

> Holt RD, Polis GA (1997) A theoretical framework for intraguild predation. Am Nat 149:745-764
Joll JW (1977) The predation of pot caught western rock lobster (Panulirus longipes cygnus) by octopus. W Aust Dept Fish Wildl Rep 29:1-58

Kats LB, Dill LM (1998) The scent of death: chemosensory assessment of predation risk by prey animals. Ecoscience 5:361-394

> Lavalli KL, Spanier E (2001) Does gregariousness function as an antipredator mechanism in the Mediterranean slipper lobster, Scyllarides latus? Mar Freshw Res 52:1133-1144

Lear JA (2004) Strong interactions between juvenile Caribbean spiny lobster (Panulirus argus) and Caribbean reef octopus (Octopus briareus) in hardbottom habitats in the Florida Keys. MS thesis, Old Dominion University, Norfolk, VA

Lima SL (1998) Nonlethal effects in the ecology of predator-prey interactions. Bioscience 48:25-34

Menge BA, Sutherland JP (1976) Species diversity gradients: synthesis of the roles of predation, competition, and temporal variation. Am Nat 110:351-369

Mills DJ, Johnson CR, Gardner C (2008) Bias in lobster tethering experiments conducted for selecting low-predation release sites. Mar Ecol Prog Ser 364:1-13

> Mintz JD, Lipcius RN, Eggleston DB, Seebo MS (1994) Survival of juvenile Caribbean spiny lobster: effects of shelter size, geographic location and conspecific abundance. Mar Ecol Prog Ser 112:255-266

Morin P (1999) Productivity, intraguild predation, and population dynamics in experimental food webs. Ecology 80: $752-760$

Neill SRSJ, Cullen JM (1974) Experiments on whether schooling by their prey affects the hunting behaviour of cephalopods and fish predators. J Zool 172:549-569

Omori K, Kikutani Y, Bangban I, Goda Y (2006) Size-dependent intraguild reciprocal predation between Helica tridens de Haaan and $H$. japonica Sakai and Yatsuzuka (Decapoda: Grapsidae) as analyzed in field experiments. J Crustac Biol 26:148-153

> Peterson CH, Black R (1994) An experimentalist's challenge: when artifacts of intervention interact with treatments. Mar Ecol Prog Ser 111:289-297

> Polis GA, Holt RD (1992) Intraguild predation: the dynamics of complex trophic interactions. Trends Ecol Evol 7: 151-154

Polis GA, McCormick SJ (1986) Scorpions, spiders and solpugids: predation and competition among distantly related taxa. Oecologia 71:111-116

Polis GA, Myers CA, Holt RD (1989) The ecology and evolution of intraguild predation: potential competitors that eat each other. Annu Rev Ecol Syst 20:297-330

Schmitt RJ (1987) Indirect interactions between prey: apparent competition, predator aggregation, and habitat segregation. Ecology 68:1887-1897

Schratwieser J (1999) The impact of resident and transient predators on the population dynamics of juvenile Caribbean spiny lobster (Panulirus argus) in Florida Bay, Florida. MS thesis, Old Dominion University, Norfolk, VA

Smith KN, Herrnkind WF (1992) Predation on early juvenile Caribbean spiny lobsters Panulirus argus (Latreille) influence of size and shelter. J Exp Mar Biol Ecol 157:3-18

Spanier E, Zimmer-Faust RK (1988) Some physical properties of shelter that influence den preference in spiny lobsters. J Exp Mar Biol Ecol 121:137-149

Zar JH (1999) Biostatistical analysis, 4th edn. Prentice Hall, Upper Saddle River, NJ

Zimmer-Faust RK (1989) The relationship between chemoreception and foraging behavior in crustaceans. Limnol Oceanogr 34:1367-1374

Submitted: May 15, 2007; Accepted: April 20, 2009

Proofs received from author(s): June 23, 2009 